\title{
Editorial
}

\section{Solar Photovoltaic Power Plants}

\author{
Md. Rabiul Islam, ${ }^{1}$ Wei $\mathrm{Xu}^{2}$ Youguang Guo, ${ }^{3}$ and $\mathrm{Ke} \mathrm{Ma}^{4}$ \\ ${ }^{1}$ Rajshahi University of Engineering and Technology, Rajshahi, Bangladesh \\ ${ }^{2}$ Huazhong University of Science and Technology, Wuhan, China \\ ${ }^{3}$ University of Technology Sydney, Ultimo, NWS, Australia \\ ${ }^{4}$ Aalborg University, Aalborg, Denmark \\ Correspondence should be addressed to Md. Rabiul Islam; rabiulbd@hotmail.com
}

Received 23 April 2017; Accepted 24 April 2017; Published 8 June 2017

Copyright (c) 2017 Md. Rabiul Islam et al. This is an open access article distributed under the Creative Commons Attribution License, which permits unrestricted use, distribution, and reproduction in any medium, provided the original work is properly cited.

In 2014, the global primary energy consumption was 12,928.4 million tons of oil equivalent which generates about 10,000 million tons of carbon during the burning of fossil fuels. The global energy crisis and environmental degradation problems have led to the rapid development of solar photovoltaic (PV) power plants to replace conventional power plants. Solar PV power plants of more than $10 \mathrm{MW}$ in capacity have thereby become a reality. Future solar PV power plants will have higher power capacity. Indeed, some of them will exceed $1000 \mathrm{MW}$. Up to 2014, about 1600 installations worldwide were PV power plants larger than $4 \mathrm{MW}$. A $10 \mathrm{MW}$ solar PV power plant may save about 15,000 tons of $\mathrm{CO}_{2}$ emissions per annum. More than $90 \%$ of the installed capacity consists of grid-connected systems. Since multimegawatt PV power plants require large areas of land, they are usually installed in remote areas, far from cities. For power transmission, a medium voltage network is commonly used.

The power converter topology, system stability, and control of grid-connected PV power plants have attracted considerable interest in recent years, as the existing technologies are not suitable for large-scale PV power plants yet. In the last two decades, extensive research has been carried out in proposing new inverter topologies. Besides the development of inverter topologies, considerable efforts have also been directed toward the progress of maximum power point tracking algorithms and grid stability and control, due to the intermittent nature of solar energy source. In order to push this emerging technology, more research is needed to solve two enormous challenges, that is, energy and environment by replacing conventional power plants with solar PV power plants.

We received a total of 21 manuscripts, of which 7 were selected for publication on various aspects of PV through the strict experts' peer reviews. A brief description and salient results of the papers to be published in the special issue are given below.

The paper "Modeling and Analysis of New Multilevel Inverter for Solar Photovoltaic Power Plant" by X. Guo et al. explores a novel five-level inverter for the high-voltage PV power plant applications. The model of the inverter is analyzed. With the redundant switching states, a new modulation strategy is proposed to reduce the common-mode voltage and electromagnetic interference. O. P. Akkaş et al.'s paper "Optimal Site Selection for a Solar Power Plant in the Central Anatolia Region of Turkey" describes the criteria for selecting the appropriate location of solar PV power plants by the multicriteria decision-making methods. The results are evaluated for 5 cities in the central Anatolian region of Turkey. The paper by $\mathrm{C}$. $\mathrm{Mu}$ et al. entitled "Observer-Based Load Frequency Control for Island Microgrid with Photovoltaic Power" investigated the load frequency control of an island microgrid with PV power and electric vehicles (EVs), where the EVs can be treated as distributed energy storages. Considering the disturbances from load change and PV power, an observer-based integral sliding mode controller is designed to regulate the frequency back to the prescribed value, where the neural network 
observer is used to estimate online the PV power. Research paper "Synergetic Control of Grid-Connected Photovoltaic Systems" by J. Qian presents synergetic control for the control of a grid-connected PV system. Modeling of a gridconnected PV system is described, and differential-algebra equations are obtained. Two control strategies are used in normal operation and during low-voltage ride-through of a PV system. Practical synergetic controllers with two control strategies are synthesized. The mathematical expressions are derived for computing control variables. In paper by $\mathrm{O}$. Taşkın et al. entitled "Analysis on Photovoltaic EnergyAssisted Drying of Green Peas", a PV energy-assisted industrial dryer has been tested in various weather and working conditions. A. Jahid et al.'s paper "PV-Powered CoMPBased Green Cellular Networks with a Standby Grid Supply" proposes a novel framework for PV-powered cellular networks with a standby grid supply and essential energy management technique for achieving envisaged green networks. The proposal considers an emerging cellular network architecture employing two types of coordinated multipoint (CoMP) transmission techniques for serving the subscribers. Under the proposed framework, each base station is powered by an individual PV solar energy module having an independent storage device. The paper by $\mathrm{H}$. A. Hussein et al. entitled "Improving the Hybrid Photovoltaic/Thermal System Performance Using Water-Cooling Technique and $\mathrm{Zn}-\mathrm{H}_{2} \mathrm{O}$ Nanofluid" is devoted to an enhancement of the performance of PV panel under different operating conditions. A new design of active cooling technique is constructed which consists of a small heat exchanger and water circulating pipes placed at the PV rear surface to solve the problem of high heat stored inside the PV cells during the operation.

We hope that this issue will promote new research directions to address the undergoing challenges and technological requirements in solar PV power plants.

\section{Acknowledgments}

We would like to take this opportunity to thank all the authors who are interested in publishing their articles in this special issue. Our specific thanks will be to the editorial board members of this journal; without their help and contribution, this issue will never be concluded in due course.

Md. Rabiul Islam

Wei Xu

Youguang Guo

$\mathrm{Ke} M a$ 

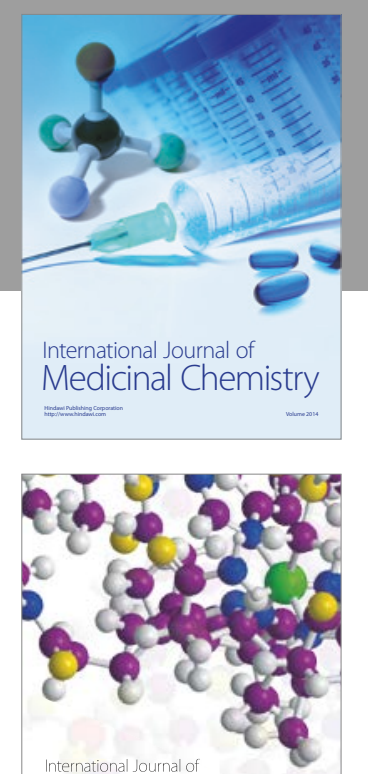

Carbohydrate Chemistry

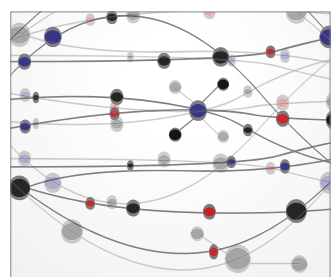

The Scientific World Journal
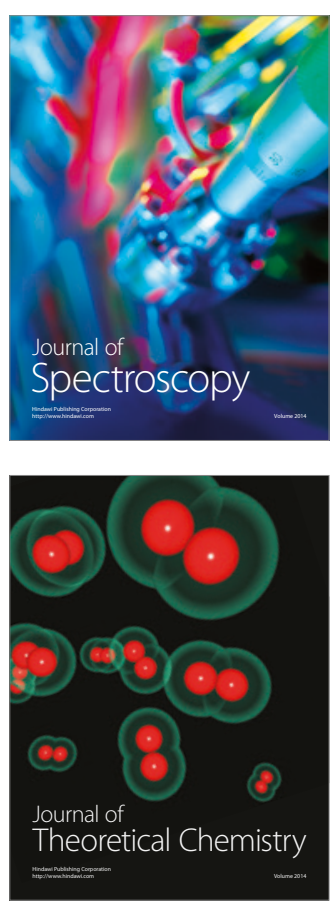
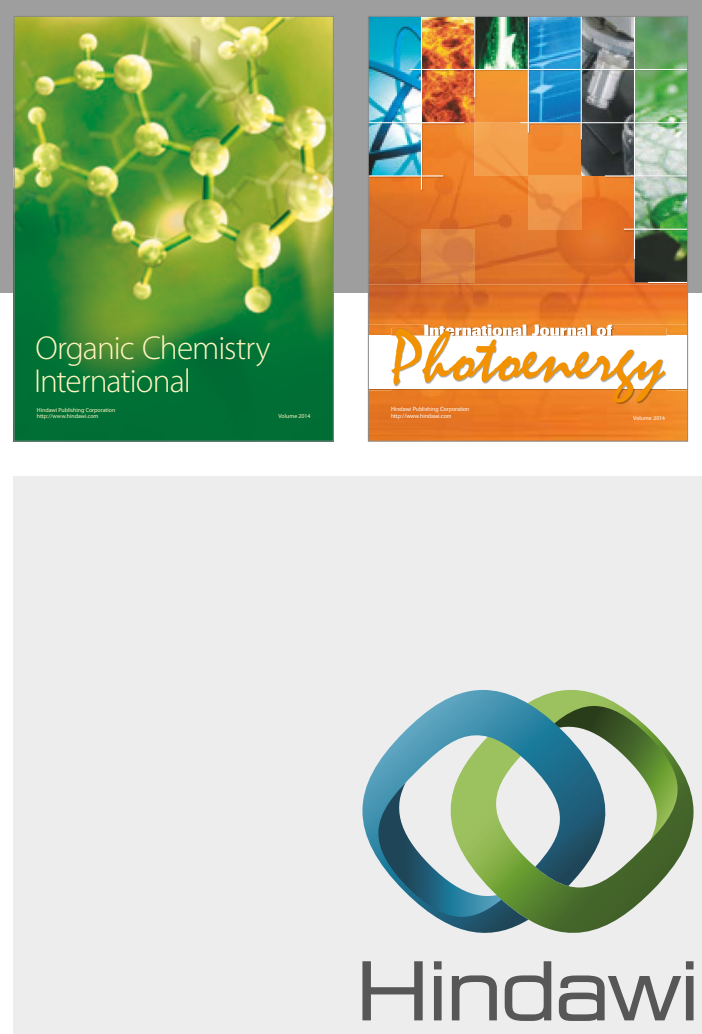

Submit your manuscripts at

https://www.hindawi.com

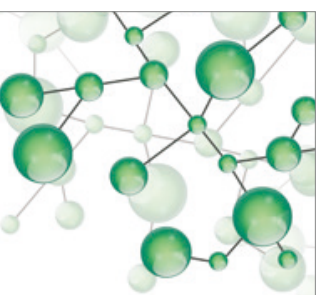

International Journal of

Inorganic Chemistry

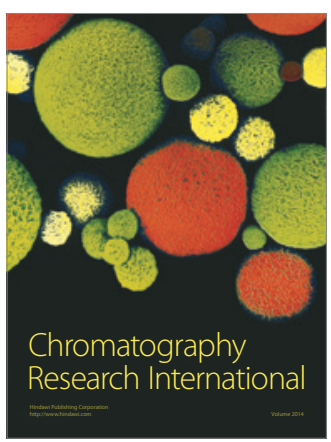

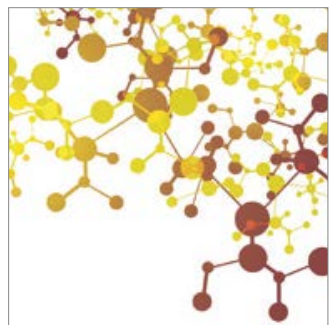

Applied Chemistry
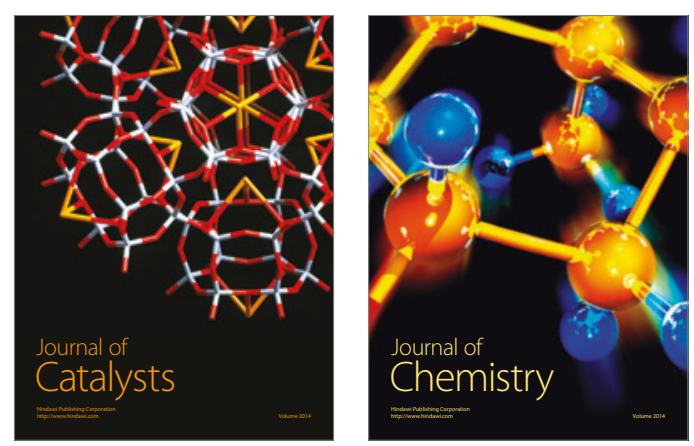
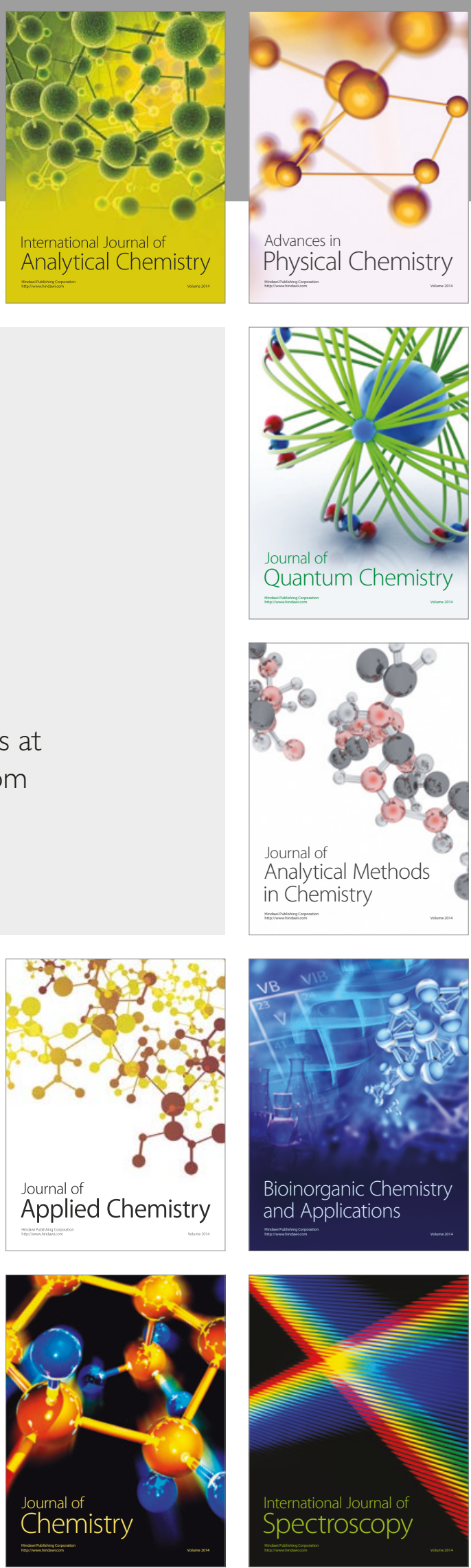